\title{
Anti-tumor and Chemoprotective Effect of Bauhinia tomentosa by Regulating Growth Factors and Inflammatory Mediators
}

\author{
Narayanan Kannan, Kunnathur Murugesan Sakthivel, Chandrasekaran \\ Guruvayoorappan
}

\begin{abstract}
Cancer is a leading cause of death worldwide. Due to the toxic side effects of the commonly used chemotherapeutic drug cyclophosphamide (CTX), the use of herbal medicines with fewer side effects but having potential use as inducing anti-cancer outcomes in situ has become increasingly popular. The present study sought to investigate the effects of a methanolic extract of Bauhinia tomentosa against Dalton's ascites lymphoma (DAL) induced ascites as well as solid tumors in BALB/c mice. Specifically, $B$. tomentosa extract was administered intraperitonealy (IP) at $10 \mathrm{mg} / \mathrm{kg}$. BW body weight starting just after tumor cell implantation and thereafter for 10 consecutive days. In the ascites tumor model hosts, administration of extract resulted in a $52 \%$ increase in the life span. In solid tumor models, co-administration of extract and CTX significantly reduced tumor volume (relative to in untreated hosts) by $73 \%$ compared to just by $52 \%$ when the extract alone was provided. Co-administration of the extract also mitigated CTX-induced toxicity, including decreases in WBC count, and in bone marrow cellularity and $\alpha$-esterase activity. Extract treatment also attenuated any increases in serum levels of TNF $\alpha$, iNOS, IL-1ß, IL-6, GM-CSF, and VEGF seen in tumor-bearing hosts. This study confirmed that, the potent antitumor activity of B.tomentosa extract may be associated with immune modulatory effects by regulating anti-oxidants and cytokine levels.
\end{abstract}

Keywords: Bauhinia tomentosa - anti-tumor activity - cyclophosphamide - Dalton's ascites lymphoma.

Asian Pac J Cancer Prev, 16 (18), 8119-8126

\section{Introduction}

Cancer is one of the leading cause of death among humans and is characterized by uncontrolled growth and spread of abnormal cells. Scientific investigations are making best efforts to combat this disease, but the sureshot, perfect cure is yet to be brought into world medicine. There are several external factors (tobacco, chemicals and radiation) and internal factors (inherited mutations, hormones etc.) leading in the initiation or promotion of carcinogenesis (Grivennikov et al 2010). There are several therapies available to treat cancer and the major one among them is radiotherapy and chemotherapy. Even though these therapies have shown promising results, some of the major drawbacks of this therapy are toxic side effects and suppression of the immune system. (Diwanay et al., 2004).

Cyclophosphamide (CTX) belongs to a group of alkylating agents used widely to treat several types of cancer and autoimmune disorders (Haque et al., 2003). CTX has been reported to disturb fundamental mechanisms concerned with cell growth differentiation and function (Alenzi et al., 2010), this chemotherapeutic has also been reported to induce several toxic side effects like nausea, fatigue, hair loss, and to cause reduction in host levels of immune cells (Kiuchi et al., 2009). Due to the toxic side effects of CTX, the need for new drugs effective against solid tumors is an important and necessary strategy to improve the arsenal of agents that could be used during chemotherapy. There has been growing interest in alternative therapies and therapeutic use of natural products, especially those derived from plants (Sakthivel and Guruvayoorappan, 2013). Of the latter class, only a small percentage $(10 \%)$ has been investigated phytochemically and an even smaller percentage properly studied in terms of pharmacological properties (Rates, 2001). Natural products represent over $50 \%$ of all drugs in clinical use and about $85 \%$ of traditional medicine involves use of plant extracts; many have been reported to possess several pharmacologically important components.

Bauhinia tomentosa (family: Caesalpiniaceae) is a medicinal plant widely distributed in tropical/subtropical regions. Many Bauhinia species are rich in $\beta$-sitosterol, lupeol, ascorbate (vitamin C), campferol, flavonone, quercetin, etc. and have been shown to impart anti-tumor, -ulcer, -bacterial, and -fungal effects (Rajkapoor, 2006). Bauhinia tomentosa has been reported to impart antioxidant (Mannangatti et al., 2010), -diabetes (Devaki et al., 2011), and -microbial effects (Gopalakrishnan and Vadivel, 2011). Preparations of B. tomentosa have been shown to stimulate the immune system and act as potential anti-inflammatory agents (Kannan et al., 2010). Aderogha et al. (2008) reported the ethanolic extract of $B$. 
tomentosa leaves contain significant levels of campferol7-O-rhamnoside, campferol-3-O-glucoside, quercetin3-O-glucoside, and quercetin-3-O-rutinoside. Building on those finding, the present study evaluated potential anti-tumor effects of an extract of $B$. tomentosa against Dalton Ascites Lymphoma (DAL)-induced ascites and solid tumor formation.

\section{Materials and Methods}

\section{Preparation and administration of plant extract}

B. tomentosa leaves were collected from Coimbatore, India. The plant was identified and authenticated at the Botanical Survey of India, Coimbatore (No: BSI/ SRC/5/23/2011-12/Tech-756). Air-dried whole plants of $B$. tomentosa were powdered and extracted (10g) overnight in $100 \mathrm{ml}$ of $70 \%$ methanol with stirring. Supernatant was collected after centrifuging at 5,000 rpm for $10 \mathrm{~min}$. Methanol was removed by evaporation and yield of the extract was $12 \%$ (w/w). For in vivo studies, a fixed amount of the dried extract was suspended in $1 \%$ gum acacia to provide a solution that would yield a dosage of $10 \mathrm{mg} / \mathrm{kg}$. BW. body weight via intraperitoneal injection $(100 \mu \mathrm{l} / \mathrm{dose})$. This dose was selected according to a cytotoxicity study of $B$. tomentos $a$ extract reported by Deveki et al. (2011).

\section{Chemicals}

Cyclophosphamide (CTX; LEDOXAN ${ }^{\mathrm{TM}}$ ) was obtained from Dabur Pharma Ltd. (New Delhi, India). DTNB (5-5'-dithiobis-2-nitrobenzoic acid) was purchased from SISCO Research Labs (Mumbai, India). Alanine aminotransferase (ALT), aspartate aminotransferase (AST), urea, and creatinine analyzing kits were obtained from SPAN Diagnostics Ltd. (Surat, India). All other chemicals used in the study were of analytical reagent grade. $\gamma$-glutamyl transpeptidase kit was purchased from MerckTM, Mumbai, India. Highly specific quantitative sandwich ELISA kits specific for evaluating levels of mouse interleukin (IL)-1 $\beta$, IL-6, IL-2, GM-CSF, VEGF, and interferon (IFN)- $\gamma$ were procured from Koma Biotech $^{\mathrm{TM}}$, (Seoul, Korea). Kits for measuring tumor necrosis factor (TNF)- $\alpha$ and iNOS were bought from USCN Life Sciences (Hubei, China). The limit of sensitivity of the IL-1 $\beta$, IL-6, IL-2, TNF $\alpha$, iNOS, VEGF, IFN $\gamma$, and GM-CSF kits were, respectively, 15, 5, 4, 3, $6.5,23,23$ and $8 \mathrm{pg} / \mathrm{ml}$.

\section{Animals}

Adult male Balb/c mice (4-6-wk-of-age, 23-25g) were purchased from Kerala Veterinary and Animal Sciences University (Mannuthy, India). The animals were kept under specific pathogen-free conditions in facilities maintained at $24[ \pm 2]^{\circ} \mathrm{C}$ and a $50 \%$ relative humidity and with a 12-hr light: dark cycle. All mice were provided ad libitum access to normal mouse chow (Sai Durga Feeds, Bangalore, India.) and filtered water. All the animal experiments were performed after obtaining permission (IAEC/KU/BT/13/08) from the Institutional Animal Ethics Committee, Karunya University.

\section{Tumor cells}

Dalton Ascites Lymphoma (DAL) cells were obtained from the Amala Cancer Research Institute Thrissur, India. The DAL cells were maintained in vivo in normal Balb/c mice by intra- peritoneal (IP) inoculation of $10^{6}$ cells into a new mouse after every 10 days.

Assessment of effect of $B$. tomentosa extract on DALinduced ascites and tumor formation

The mice were randomly allocated into four groups ( $n=15$ /group). Mice in Group I were to serve as a normal control and to be treated with saline. Mice in Group II were to serve as DAL only controls. Mice in Group III were to be treated with the DAL and also with the $B$. tomentosa extract (at $10 \mathrm{mg} / \mathrm{kg}$. BW). Mice in Group IV were to be treated with DAL and also with methotrexate (at $3.5 \mathrm{mg}$ / $\mathrm{kg}$. BW). DAL cells were collected from donor mice (on Day 9 after initial injection), suspended in sterile saline, and their viability and concentration determined via trypan blue exclusion. Except for mice in Group I, all mice were injected IP with $1.5 \times 10^{6}$ DAL cells; this was designated as Day 0. The respective treatments were to continue daily up to 10 days post-injection of the DAL cells. Body weights of the mice were recorded at the beginning of the experiment (Day 0) and every 5 days over the course of the treatment period.

On Days 10 and 15, subsets of mice $(n=6)$ from each group were euthanized by cervical dislocation and ascites fluid was recovered; blood was also collected (by cardiac puncture) to permit estimation of hemoglobin content $(\mathrm{Hb})$ and white blood cell (WBC) levels. Other samples of the blood were processed to yield serum for subsequent analyses of various parameters (see below). The remaining three mice in each group were maintained to monitor lifespan. Mean survival times across the treated groups were compared with the DAL control group using the calculation Mean Survival Time $(M S T)=($ Day of first death + Day of last death)/2. The Percentage Increase in Lifespan (\% ILS), a reflection of anti-tumor efficacy of a given treatment, was calculated as $100 \times$ [(MST of treated group) - (MST of DAL control group)]/MST of DAL control group (Huang et al., 1984).

\section{Effect of extract against DAL-induced solid tumor and cyclophosphamide (CTX) toxicity}

Another set of mice was randomly allocated into seven groups ( $n=18 /$ group). Mice in Group I were to serve as a normal control and to be treated with saline. Mice in Group II were to be treated with CTX only $(25 \mathrm{mg} / \mathrm{kg}$. BW). Mice in Group III were to be treated only with $25 \mathrm{mg}$ $\mathrm{CTX} / \mathrm{kg} \mathrm{BW}$ and B. tomentosa extract (10 mg/kg. BW). Mice in Group IV were to serve as DAL only controls. Mice in Group V were to be treated with the DAL and

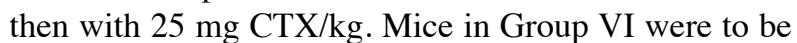
treated with the DAL and then $B$. tomentosa extract (10 $\mathrm{mg} / \mathrm{kg}$. BW). Group VII were to be treated with the DAL and then with $25 \mathrm{mg} \mathrm{CTX} / \mathrm{kg}$ and $B$. tomentosa extract $(10 \mathrm{mg} / \mathrm{kg}$. BW). As before, DAL cells were collected from donor mice, suspended in sterile saline, and their viability/concentration determined via trypan blue exclusion. Except for mice in Groups I-III, all other mice 
were injected IP with $1.5 \times 10^{6}$ DAL cells on Day 0 . The respective treatments were to continue daily up to 10 days post-injection of the DAL cells.

Body weights of the mice were recorded at the beginning of the experiment (Day 0) and every 5 days over the course of the treatment period. Tumor mass in each Group IV-VII mouse was measured starting on Day 3 after tumor cell injection. Measures of tumor radii (performed at right angles to one another) were taken every $3 \mathrm{~d}$ for a period of 30 days. Volume of the tumor mass was calculated using $\mathrm{V}=[4 / 3] \pi \mathrm{r} 1^{2} \mathrm{r} 2$, where $\mathrm{r} 1$ and $\mathrm{r} 2$ are the radii of the tumor (Majumdar, 1997). During this same period, blood from six mice/group was collected from the tail vain and total WBC (white blood cell) counts performed using a hemocytometer. A baseline value was also obtained on Day 0 from all mice and prior to injection of Group IV-VII mice with tumor cells.

At time of sacrifice on day 10 and day 15 post-tumor injection, 6 mice from each group were euthanized and their femurs collected to permit analyses of bone marrow samples. Blood was also collected for analysis (see below). Specifically, marrow cells were collected from both femurs and made into single cell suspensions and aliquots placed on glass slides (and stained with hematoxylin) for evaluation of non-specific $\alpha$-esterase activity (using azodye coupling method; Bancroft and Cook, 1984). The remaining three mice in each group were maintained to monitor lifespan/tumor growth.

Effect of extract on serum TNF $\alpha, i N O S, I L-1 \beta, I L-6, I L-2$, IFN $\gamma$, GM-CSF, VEGF levels

Blood was collected from each animal on Days 15 and 30 and the corresponding serum assessed for tumor necrosis factor (TNF)- $\alpha$, iNOS, interleukin (IL)- $1 \beta$, IL-6, IL-2, interferon (IFN)- $\gamma$, GM-CSF, and VEGF levels using highly specific quantitative sandwich ELISA kits. The kits for evaluating mouse IL-1 $\beta$, IL-6, IL-2, GM-CSF, VEGF, and IFN $\gamma$ were procured from Koma BiotechTM (Seoul, Korea). Kits for measuring TNF $\alpha$ and iNOS were from USCN Life Sciences (Hubei, China). Limit of sensitivity of the IL-1 $\beta$, IL-6, IL-2, TNF $\alpha$, iNOS, VEGF, IFN $\gamma$, and GM-CSF kits were, respectively, 15, 5, 4, 3, 6.5, 23, 23 and $8 \mathrm{pg} / \mathrm{ml}$.

\section{Statistical analysis}

All values are expressed as mean \pm SD. For each endpoint, group means were compared using a one-way analysis of variance (ANOVA) followed by a Dunnett's post-hoc test (Instat Version 3.0 software; Graphpad, San Diego, CA). A p-value $<0.05$ was considered significant.

\section{Results}

Changes in MST and \%ILS due to B. tomentosa extract Mice injected with DAL cells (control) had an MST of 16.60 [ \pm 1.03$]$ days. This value was significantly increased to 25.33 [ \pm 2.07$]$ days due to the $B$. tomentosa extract treatment. These results are almost comparable to that of cyclophosphamide (CTX), the standard drug for which the MST was $29.83[ \pm 1.16]$ days. The \% ILS of treated mice increased $52 \%$ compared to that of the DAL-bearing control hosts. In addition, the body weights of DAL tumor control mice increased $39 \%$ (relative to Group 1 mice controls); this value was reduced $\approx 17 \%$ due to the treatment with $B$. tomentosa (Table 1). These changes are important as host body weight is directly reflective of increases in DAL tumor volume in the peritoneal cavity.

Effect of extract on hemoglobin and WBC counts in DALbearing mice

The hemoglobin $(\mathrm{Hb})$ content in the DAL control mice was decreased $(10.22[ \pm 0.39] \mathrm{gm} \%)$ compared to that in normal mice $(15.72[ \pm 0.40] \mathrm{gm} \%)$. Treatment with B.tomentos $a$ at of $10 \mathrm{mg} / \mathrm{kg}$. BW amplified the $\mathrm{Hb}$ content to moreover normal levels by Day $15(15.78[ \pm 0.42]$ gm \%). Total WBC counts in DAL control mice were increased $\left(15.54 \times 10^{3}\right.$ cells $\left./ \mathrm{mm}^{3}\right)$ compared to those in with normal mice $\left(11.0^{3} \times 10^{3}\right.$ cells $\left./ \mathrm{mm}^{3}\right)$. Administration of the test extract led to reductions in the WBC counts on both Days 10 and 15 (respectively, 11.14 and $14.26 \times 10^{3}$ cells $/ \mathrm{mm}^{3}$ ) compared to those seen in the DAL control hosts (Figure 1).

\section{Effect of extract on body weight changes due to DAL tumor and/or CTX treatment}

Changes in host body weight during the experimental period (recorded before and every third day of experiment - up to Day 30) are shown in Figure 2. The results indicate CTX-treated mice had reduced body weight gains

Table 1. Effect of B.tomentosa on Mean Survival Time (MST), Percentage increase in Lifespan and Body weight

\begin{tabular}{|c|c|c|c|}
\hline \multirow[t]{2}{*}{ Treatment design } & \multirow[t]{2}{*}{ MST (in days) } & \multicolumn{2}{|c|}{ Percentage increase in } \\
\hline & & life span & Bodyweight \\
\hline Control & $>50$ & -- & 10.29 \\
\hline DLA Tumor Control & $16.60 \pm 1.03$ & -- & 38.77 \\
\hline Tumor + & & & \\
\hline $\begin{array}{l}\text { Methotrexate } \\
(3.5 \mathrm{mg} / \mathrm{Kg} / \mathrm{B} . w \mathrm{t})\end{array}$ & $29.83 \pm 1.16^{* *}$ & $79 \%$ & 13.58 \\
\hline $\begin{array}{l}\text { B.tomentosa } \\
(10 \mathrm{mg} / \mathrm{Kg} / \mathrm{B} . w \mathrm{t})\end{array}$ & $25.33 \pm 2.07 * *$ & $52 \%$ & 16.70 \\
\hline
\end{tabular}

*The results are expressed as the mean of each group $(\mathrm{n}=6)$ and ** statistically significant different $(\mathrm{p}<0.01)$ from DLA tumor control animals.

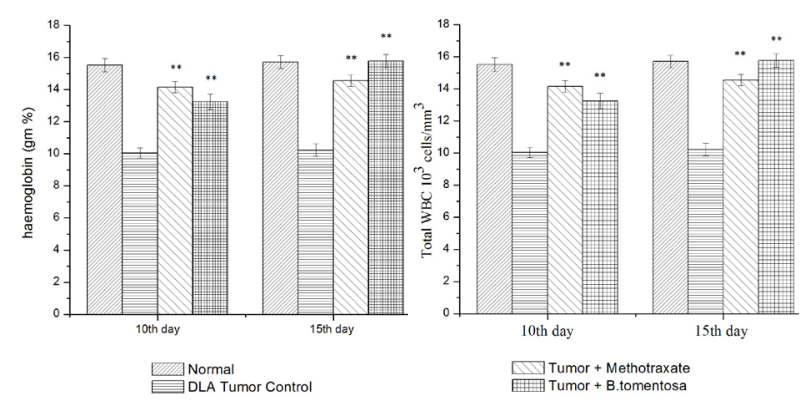

Figure 1. Effect of B.tomentosa on Haemoglobin and WBC Count During DAL Bearing BALB/c Mice on 10th and $15^{\text {th }}$ Days. Mice were injected with $B$. tomentosa extract (IP; $10 \mathrm{mg} / \mathrm{kg}$. BW) daily for 10 day following initial IP injection of DAL cells ( $1.5 \times 10^{6} \mathrm{DAL} /$ mouse $)$. Values shown are means $( \pm \mathrm{SD}) ; \mathrm{n}=6 /$ group and $* *(\mathrm{P}<0.01)$ Statistically Significant different from DAL tumor control animals 
Narayanan Kannan et al

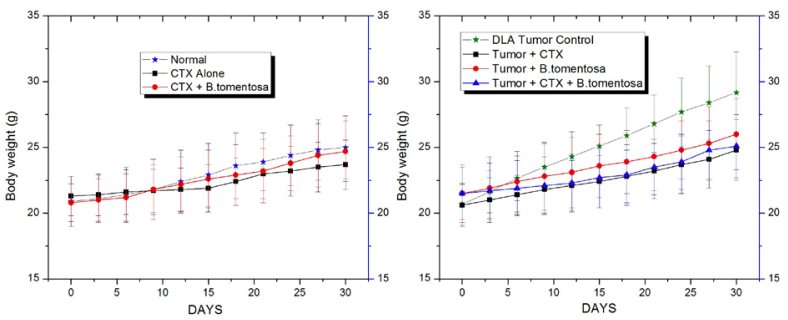

Figure 2. Effect of Bauhinia Tomentosa on Body weight During DAL Induced Solid Tumor with CTX Treatment in BALB/c Mice. Mice were injected with $B$. tomentosa extract (IP; $10 \mathrm{mg} / \mathrm{kg}$. BW) daily for 10 day following initial IP injection of DAL cells $\left(1.5 \times 10^{6} \mathrm{DAL} /\right.$ mouse). In groups receiving a CTX co-treatment, CTX $(25 \mathrm{mg} / \mathrm{kg}$. BW $)$ was given IP $1 \mathrm{hr}$ before the extract. Values shown are means $( \pm \mathrm{SD}) ; \mathrm{n}=6$ / group. Results are given as gram $(\mathrm{g})$

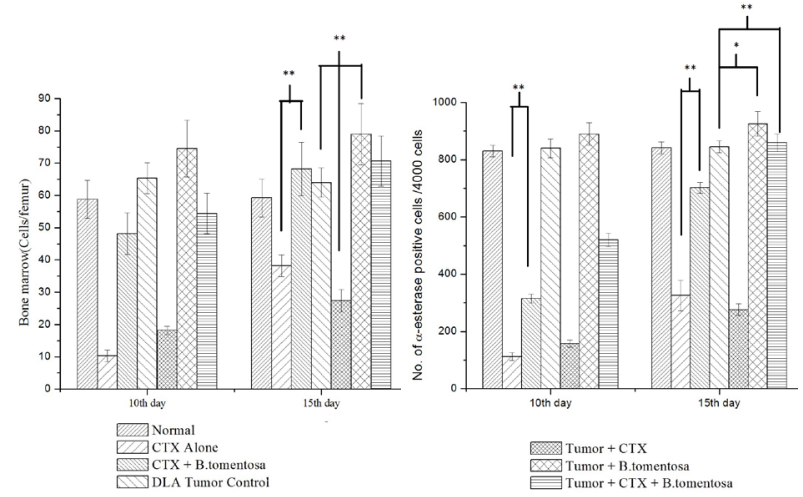

Figure 3. Effect of Bauhinia Tomentosa on Bone Marrow Cellularity and $\alpha$-Esterase Activity during DAL Induced Solid Tumor with CTX Treatment in BALB/c Mice. Mice were injected with $B$. tomentosa extract (IP; $10 \mathrm{mg} / \mathrm{kg}$. BW) daily for 10 day following initial IP injection of DAL cells $\left(1.5 \times 10^{6} \mathrm{DAL} / \mathrm{mouse}\right)$. In groups receiving a CTX co-treatment, CTX $(25 \mathrm{mg} / \mathrm{kg}$. BW $)$ was given IP $1 \mathrm{hr}$ before the extract. Values shown are means $( \pm \mathrm{SD}) ; \mathrm{n}=6$ /group. **Value significantly different from tumor control at $\mathrm{p}<0.01$

compared to normal hosts, while DAL-injected mice had increasing weights due to tumor growth. In contrast, B.tomentosa extract-treated mice shows had slower body weight gains relative to those of DAL-only mice. In mice treated with both CTX and B.tomentosa (in conjunction with DAL), body weight changes were on par with those in normal hosts.

Effect of extract on bone marrow cellularity $\backslash$-esterase activity changes due to DAL tumor/CTX

The effect of the test extract on bone marrow cellularity on Day 10 \& 15 were shown in Figure 3. By Day 15, in non-tumor cell-injected mice, those that received CTX alone had an average of $38.2[ \pm 3.3] \times 10^{5}$ cells/femur; this was significantly increased to $68.2[ \pm 8.3] \times 10^{5}$ cells/ femur by the co-administration of the extract. In tumor cell-injected mice, those that had the DAL had cell values of $\approx 64.0[ \pm 4.5] \times 10^{5}$ cells/femur at both timepoints. This values was significantly reduced by CTX treatment (to $27.4[ \pm 3.5] \times 10^{5}$ cells/femur; in mice with DAL that were treated with $B$. tomentosa extract only or with the CTX-extract co-treatment, the values increased to 79.0

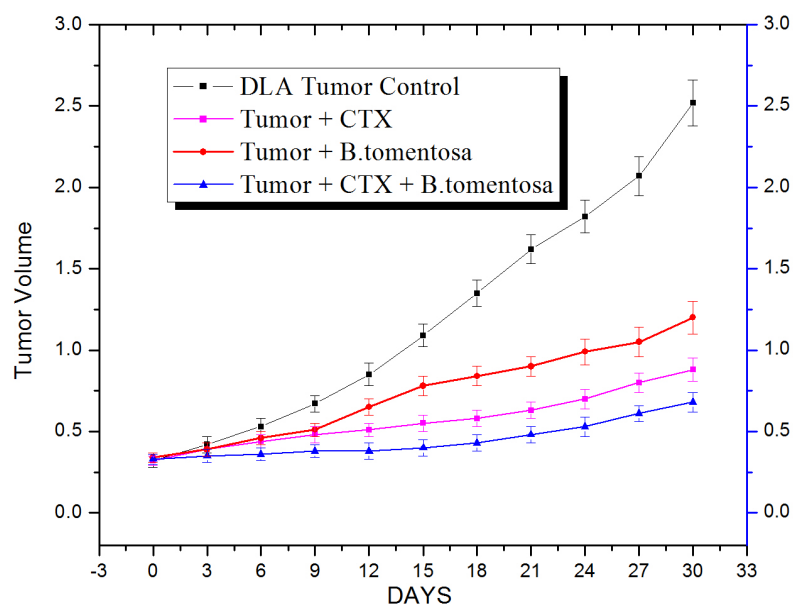

Figure 4. Effect of Bauhinia Tomentosa on Tumor Volume During DAL Induced Solid Tumor with CTX Treatment in BALB/c Mice. Mice were injected with $B$. tomentosa extract (IP; $10 \mathrm{mg} / \mathrm{kg}$. BW) daily for 10 day following initial IP injection of DAL cells ( $\left.1.5 \times 10^{6} \mathrm{DAL} / \mathrm{mouse}\right)$. In groups receiving a CTX co-treatment, CTX $(25 \mathrm{mg} / \mathrm{kg}$. BW) was given IP $1 \mathrm{hr}$ before the extract. the volume of tumor mass was calculated using the formula $V=4 / 3 \pi \mathrm{r} 12 \mathrm{r} 2$. 0th day is 24 hours before tumor implantation. Values shown are means $( \pm$ $\mathrm{SD}) ; \mathrm{n}=6$ /group. Results are given as $\mathrm{mm}^{3}$
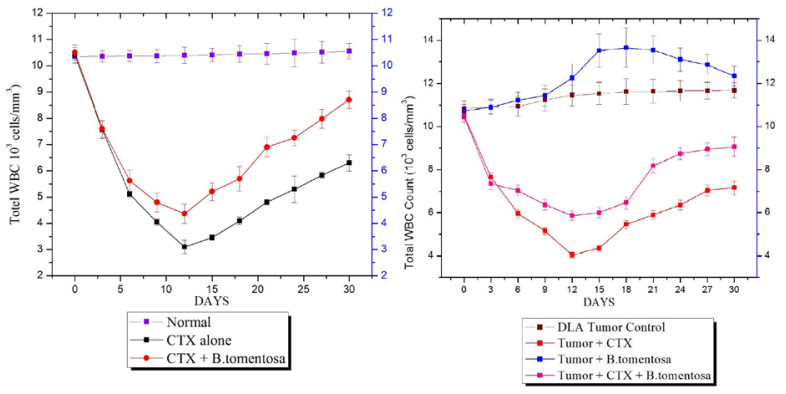

Figure 5. Effect of Bauhinia Tomentosa on WBC Count During DAL Induced Solid Tumor with CTX Treatment. Mice were injected with B. tomentosa extract (IP; $10 \mathrm{mg} / \mathrm{kg}$. BW) daily for 10 day following initial IP injection of DAL cells $\left(1.5 \times 10^{6} \mathrm{DAL} /\right.$ mouse). In groups receiving a CTX co-treatment, CTX $(25 \mathrm{mg} / \mathrm{kg}$. BW $)$ was given IP $1 \mathrm{hr}$ before the extract. Blood samples were collected by tail vain on every third day for 30 days 0 th day is 24 hours before tumor implantation. Values shown are means $( \pm \mathrm{SD}) ; \mathrm{n}=6$ /group. Results are given as $10^{3}$ cells $/ \mathrm{mm}^{3}$

$[ \pm 9.5]$ and $70.7[ \pm 7.8] \times 10^{5}$ cells/femur, respectively. The trends of effect of the extract (alone or in combination with CTX) were paralleled in the measures of $\alpha$-esterase activity (Figure 5).

Effect of extract on tumor volume changes due to DAL tumor/CTX

Effect of Bauhinia tomentosa on tumor volume during DAL induced solid tumor with CTX treatment results were shown in Figure 4. Tumor volume of DAL control animal was gradualy increasing on 30th day this level was $2.52[ \pm 0.14] \mathrm{mm}^{3}$ while CTX and B.tomentosa treated groups were significantly reduced to $0.88[ \pm 0.07]$ and $1.20[ \pm 0.10] \mathrm{mm}^{3}$, respectively, on the same day. More over the combined treatment with B.tomentos $a$ and CTX 

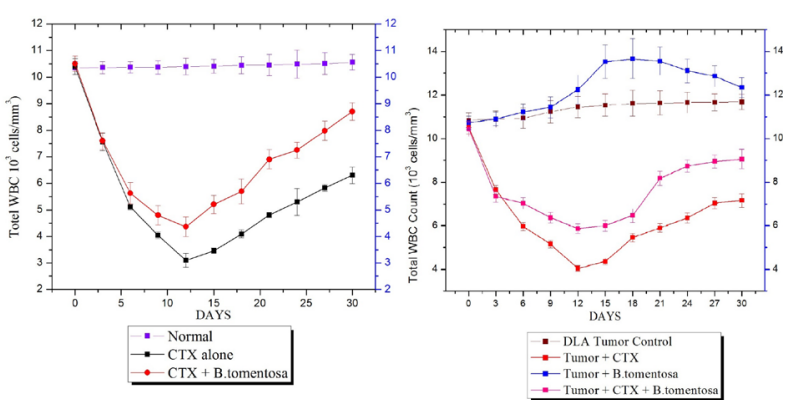

Figure 6. Effect of B. tomentosa Extract on Serum TNF- $\alpha$, i NOS, IL-1 $\beta$ and IL-6 Levels in DAL-injected hosts with and without Concurrent CTX Treatment. Mice were injected with $B$. tomentosa extract (IP; $10 \mathrm{mg} / \mathrm{kg}$. $\mathrm{BW}$ ) daily for 10 day following initial IP injection of DAL cells $\left(1.5 \times 10^{6} \mathrm{DAL} / \mathrm{mouse}\right)$. In groups receiving a CTX co-treatment, CTX $(25 \mathrm{mg} / \mathrm{kg}$. BW) was given IP $1 \mathrm{hr}$ before the extract. Blood samples were collected by cardiac puncture on Days 15 and 30, the cytokine levels assessed by ELISA. Values shown are means $( \pm S D) ; n=6 /$ group. Value significantly different from tumor control at $* \mathrm{p}<0.05, * * \mathrm{p}<0.01$
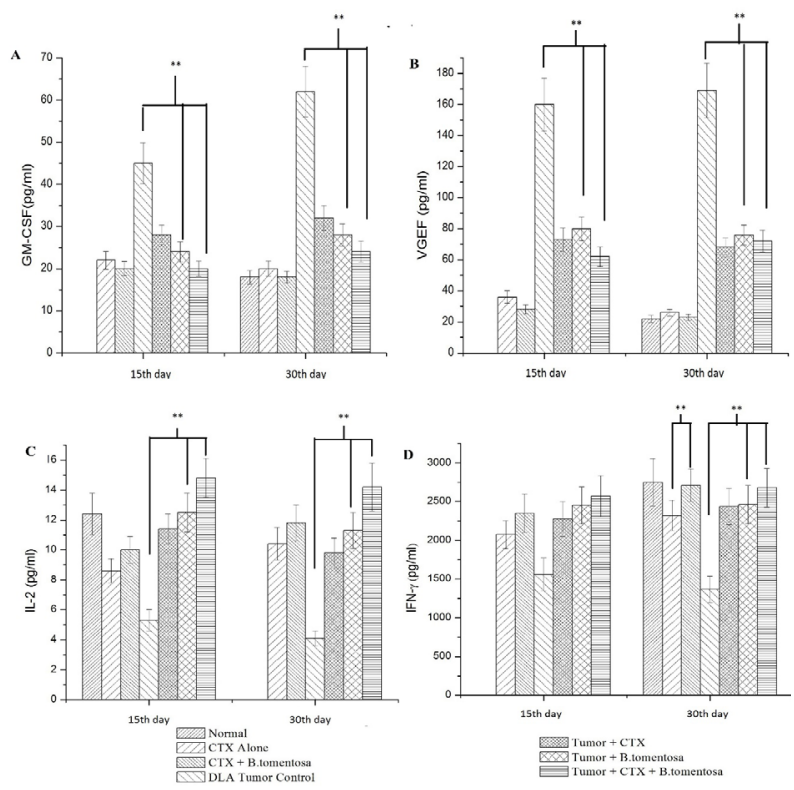

Figure 7. Effect of B.tomentosa Extract on Serum GMCSF, VEGF, IL-2, and IFN $\gamma$ levels in DAL-injected hosts with and without Concurrent CTX Treatment. Mice were injected with $B$. tomentosa extract (IP; $10 \mathrm{mg} / \mathrm{kg}$. BW) daily for 10 day following initial IP injection of DAL cells (1.5 x $10^{6} \mathrm{DAL} /$ mouse). In groups receiving a CTX co-treatment, CTX $(25 \mathrm{mg} / \mathrm{kg}$. BW) was given IP $1 \mathrm{hr}$ before the extract. Blood samples were collected by cardiac puncture on Days 15 and 30, the cytokine levels assessed by ELISA. Values shown are means $( \pm \mathrm{SD}) ; \mathrm{n}=6$ /group. ${ }^{* *}$ Value significantly different from tumor control at $\mathrm{p}<0.01$.

treated group resulted more reduction $\left(0.68 \pm 0.06 \mathrm{~mm}^{3}\right)$ then other group of animals.

\section{Effect of extract on WBC level changes due to DAL tumor/ CTX}

The mice which were treated with CTX has the total WBC count of $3.10 \pm 0.27 \times 10^{3}$ cells $/ \mathrm{mm}^{3}$ on 12 th day and the animals treated with B.tomentosa the total WBC count were $23.4 .37 \pm 0.37$ cells $/ \mathrm{mm}^{3}$ on same day. The total WBC increased evidently towards normal level. A reduction in the level of total WBC was seen in CTX treated control animals throughout the period of study. Whereas, WBC level in DAL solid tumor bearing group and DAL with B.tomentosa treated group shows gradually amplified and reach greater then a normal level $\left(11.68 \pm 0.35 \times 10^{3}\right.$ cells/ $\mathrm{mm} 3$ and $12.35 \pm 0.46 \times 10^{3}$ cells $/ \mathrm{mm}^{3}$ ) respectively, but CTX treated along with DAL and B.tomentosa treated group the WBC level was reach nearby normal level at end of the experiment. Results were shown in Figure 5.

\section{Effect of extract on changes in serum inflammatory proteins due to DAL tumor/CTX}

Serum concentrations of select inflammatory mediators were measured by ELISA. The elevated level of serum TNF $\alpha$, iNOS, IL-1 $\beta$, IL-6, GM-CSF, and VEGF in tumor control mice, were reduced in hosts that also received the B.tomentosa extract (Figures 6 and 7). The patterns of changes in IL-2 and IFN $\gamma$ levels differed from those of the other mediators, i.e., levels were lower in the tumor control hosts and then markedly elevated due to treatment with extract.

\section{Discussion}

Interest in alternative therapies using natural products for cancer treatment are increasing due to the wide range of toxic side effects of many currently-used chemotherapeutics (Jemal et al., 2009). Many plants extract and their active compounds have been studied in in vitro and in vivo cancer models (Newman and Cragg, 2012). Previous studies from our laboratory showed that B. tomentosa preparations appeared to impart various biological effects, such as acting as an immunomodulant, as well as imparting anti-oxidant, anti-inflammatory, and anti-tumor growth effect (in vitro only). (Kannan et al., 2010). The present study showed there was an anti-tumor effect induced by a $B$. tomentosa extract in vivo, in both an ascites and a solid tumor model. The preparation used here inhibited tumor/cancer growth in both models, as well as amplifications of several key hematologic parameters compared to values seen in hosts with the tumors but not receiving the extract.

Normally, ascites tumor implantation induces local inflammation and increases in vascular permeability, cellular migration and, finally, progressive ascites fluid accumulation (Deepak et al., 2009). Here, the DAL control group had a shorter survival profile than that of hosts that also received the $B$. tomentosa extract. These findings suggested to us that there was either a direct cytotoxic effect on the tumor cells by the IP-injected extract, or the induction of an indirect local effect provided (i.e., reductions in inflammation due to the anti-inflammatory activity deserved in Kannan and Guruvayoorappan (2013).

Cancer chemotherapy treatment causes myelosuppression and anemia. Anemia, mainly due to reductions in $\mathrm{RBC}$ or hemoglobin levels, may occur due to iron deficiency during cancer cell growth or other hemolytic conditions. The results of the present study clearly showed that $B$.tomentosa extract not only favored a rebound-like effect on hemoglobin levels in the DAL- 
injected hosts, but also seemed to protect their bone marrow cells. It is known that CTX has a pro-oxidant character and generates oxidative stress; metabolites of CTX also bind to DNA and cause damage (chromosomal breaks, micronuclei formation) and cell death (Murata et al., 2004; Sakthivel et al., 2012). Here, administration of B. tomentosa extract in conjunction with CTX was found to enhance total WBC counts whereas these levels were drastically reduced in mice that received CTX alone. Bone marrow cellularity was also incrased significantly in the co-treated hosts, indicating that extract appeared able to stimulate the hemato-poetic system. Moreover, there was increased presence of $\alpha$-esterase ${ }^{+}$marrow cells, suggesting to us that the extract could also enhance differentiation of stem cells. Whether the CTX-induced myelosuppression was reversed, inhibited, or both by the B. tomentosa extract remains to be more precisely defined.

In DAL control mice here, tumor volume was increased $\approx 8$-times over a 30 -d period, but only 4 - times in animals treated with B.tomentosa; the effect was even greater in hosts that received extract-CTX co-treatment (only 2-times greater). These results suggested to us that the inhibitory effect related not only reduce the side effect caused by CTX but also with the systemic disturb. Similar results were obtained by Natesan et al. (2007) using Careya arborea methanolic extract.

The role of NO levels during tumor formation is regulated by interactions between endothelial cells in the tumor and infiltrating immune cells like macrophages and T-cells (Ruttimann, 2007). The Nitric Oxide synthase (iNOS) activity during tumor formation correlated positively with tumor grade (Kolb, 2000). Taken in that context, the results of the present study concerning NO and iNOS confirmed the anti-tumor effect of the B.tomentosa extract in the mouse hosts.

Immune cells have a broad impact on tumor initiation, growth, and progression; many of these effects are mediated by pro-inflammatory cytokines. Expression of these cytokines, i.e., interleukin (IL)-6, tumor necrosis factor (TNF)- $\alpha$, IL- $1 \beta$, and IL-2, are critical mediators during tumor progression involves regulation of transcription factors and nuclear factor (NF)- $x \mathrm{~B}$ (Goldberg and Schwertfeger, 2010). Manusama et al. (1996) reported a synergetic anti-tumor effect with a combination of TNF- $\alpha$ and chemotherapeutics. One of the chemotherapeutic drug liposomal doxorubicin showed anti-tumor activity with presence of low dose of TNF- $\alpha$ in mice and rats. (Tenhagen et al., 2000). B.tomentosa treated group amplifications of TNF- $\alpha$ level may be helped to tumor suppression in extract treated group.

IL-6 is a multifunctional immunomodulatory cytokines, which activate $\mathrm{B}$ and $\mathrm{T}$ lymphocytes produced by both normal and tumor cells and also serum concentration of IL-6 can used to predict progress of tumor cells (Cheng et al., 2014). IL-1 $\beta$ involved in the proliferation, differentiation and apoptosis of cells. Inflammatory hypersensitivity has been found t1o be the result of IL$1 \beta$ activates COX-2. It has been implicated as a factor in tumor progression via the expression of metastatic and angiogenic genes and growth factors (Lewis et al., 2006). Granulocyte macrophage-colony stimulating factor (GM-
CSF) has been shown to increase the immune response both in animal models and clinical trials. (Sakthivel and Guruvayoorappan, 2013) which was consistently induces dense CD4+ and CD8+ T-lymphocyte and plasma cell infiltrates, in metastatic lesions (Soiffer et al.,1998). The critical role of GM-CSF is not well characterized but clinical trials using GM-CSF-secreting tumors cells have been reported in patients with several tumor types (Small et al., 2007; Zarei et al., 2009). Vascular endothelial growth factor (VEGF) is a potent and specific angiogenic factor, was well known to be a key requirement for tumor growth. They activate endothelial cells to proliferate and migrate, subsequently resulting in new tube formation and blood flow (Chen et al., 2014). However, the result gained in this study indicates that B.tomentosa reduced the production of TNF $\alpha$, iNOS, IL- $1 \beta$, IL-6, GM-CSF, and VEGF levels clearly express the regulatory effect of this intermediates and tumor inhibition of $B$. tomentosa.

Interleukin (IL)-2 produced by T-cells (Malek, 2003) is considered a key growth and cell death factor for antigen-activated T lymphocytes IL-2 and IL-2 receptor deficient mice exhibit lethal autoimmunity (Preethi et al., 2010). Ouyang et al. (2006) conformed that IL-2 augmented activation of (TAM) would play the main role in induction of the MHC class I molecule through secretion of IFN $\gamma$, and would contribute to the IFN $\gamma$ mediated apoptosis induction in tumor cells. IFN $\gamma$, an important immunoregulatory molecule against tumor cells, appears capable of driving novel cellular and molecular inflammatory mechanisms that may underline tumor initiation, immunoevasion, survival, and IFN- $\gamma$ could inhibit angiogenesis and cell proliferation (Blankenstein and Qin, 2003).

In conclusion, the potential anti-cancer effect of B.tomentosa was investigated and it was found that a B.tomentosa extract exhibited a strong inhibitory effect on the proliferation of both solid and ascites tumor cells. The results of this experimental study suggested that $B$. tomentosa contains some active constituents that could be useful as anti-cancer drugs. The activity of the extract could be attributed, in part, to effects on tumor cell proliferation, immune system activation, and/or a blocking (or induction) of key immune system regulatory products (including TNF $\alpha$. IL-2, IL-6, IL-1 $\beta$, GM-CSF, or IFN $\gamma$ ) that can impact on tumor cells during proliferation, cell cycle regulation, signal transduction, or even the motility and invasiveness of the cancer cells.

\section{Acknowledgements}

The authors acknowledge the valuable suggestions of Dr. J. Jannet Vennila, Director, School of Biotechnology and Health Sciences, Karunya University.

\section{References}

Aderogba MA, Mc Gaw LJ, Ogundaini AO, Eloff JN (2008). Cytotoxicity Study of antioxidant flavonoids from Bauhinia tomentosa leaf extract. Niger J Nat Prod medicine, 12, 50-4. Alenzi FQ, Bolkiny YS, Salem ML (2010). Protective effects of Nigella sativa oil and thymoquinone against toxicity 
induced by the anticancer drug cyclophosphamide. $\mathrm{Br} J$ Biomed Sci, 67, 20-8.

Bancraft JD, Cook HC (1984). Manual of histological techniques. London: Churchill-Livingstone, 171-4.

Blankenstein T, Qin Z (2003). The role of IFN $\gamma$ in tumor transplantation immunity and inhibition of chemical carcinogenesis. Curr Opin Immunol, 15, 148-54.

Chen, JD, Xiong YQ, Dong K, et al (2014). Clinical significance of joint detection of serum VEGF, SIL-2R and HGF in patients with primary hepatocellular carcinoma before and after percutaneous microwave coagulation therapy. Asian Pac J Cancer Prev, 15, 4545-8.

Cheng JC (2014). Transient knock down of grp78 reveals roles in serum ferritin mediated pro sin aammatory cytokine secretion in rat primary activated hepatic stellate cells. Asian Pac J Cancer Prev, 15, 605-10.

Corti A, Franzini M, Paolicchi A, Pompella A (2010). $\gamma$-Glutamyl-transferase of cancer cells: At the crossroads of tumor progression, drug resistance, and drug targeting. Anticancer Res, 30, 1169-81.

Deepak P, Kumar S, Acharya A (2008). Overexpression of IL-13 in a murine T-cell lymphoma: A possible factor of DL-induced immunosuppression and tumor progression. Cancer Invest, 27, 641-49.

Devaki K, Beulah U, Akila G, Narmadha R, Gopalakrishnan VK (2011). Glucose lowering effect of aqueous extract of Bauhinia tomentosa on alloxan-induced Type 2 diabetes mellitus in Wistar rats. J Basic Clin Pharm, 2, 167-74.

Diwanay S, Chitre D, Patwardhan B (2004). Immunoprotection by botanical drugs in cancer chemotherapy. J Ethnopharmacol, 90, 49-55.

Dominici S, Valentini M, Maellaro E, et al (1999). Redox modulation of cell surface protein thiols in U937 lymphoma cells: the role of gamma-glutamyl transpeptidase-dependent $\mathrm{H}_{2} \mathrm{O}_{2}$ production and S-thiolation. Free Radic Biol Med, 27, 623-35

Goldberg JE, Schwertfeger KL (2010). Proinflammatory cytokines in breast cancer: mechanisms of action and potential targets for therapeutics. Curr Drug Targets, 11, 1133-46.

Gopalakrishnan S, Vadivel E (2011). Antibacterial and antifungal activity of the bark of bauhinia tomentosa. Int J Pharm. Sci, 2, 104-9.

Green LC, Wagner, DA, Glogowski J, et al (1982). Analysis of nitrate, nitrite, and $[15 \mathrm{~N}]$ nitrate in biological fluids. Anal Biochem, 126, 131-8.

Grivennikov SI, Greten FR, Karin M (2010). Immunity, inflammation, and cancer. Cell, 140, 883-99.

Haque R, Parvez S, Pandey S (2003). Aqueous extract of walnut (juglans regia 1.) protects mice against cyclophosphamide induced biochemical toxicity. Hum Exp Toxicol, 22, 473-80.

Huang MT, Wood AW, Newmark HL (1984). Inhibition of the mutagenicity of bay-region diol epoxides of polycyclic aromatic hydrocarbons by phenolic plant flavonoids. Carcinogenesis, 4, 1631-37.

Jemal A, Siegel R, Ward, E, et al (2009). Cancer statistics 2009. CA Cancer J Clin, 59, 225-49.

Kannan N, Guruvayoorappan C (2013). Protective effect of Bauhinia tomentosa on acetic acid induced ulcerative colitis by regulating antioxidant and inflammatory mediators. Int Immunopharmacol, 16, 57- 66.

Kannan N, Renitta RE, Guruvayoorappan C (2010). Bauhinia tomentosa stimulates the immune system and scavenges free radical generation in vitro.J Basic Clin Physiol Pharmacol, 21, 157-68.

Kiuchi H, Takao T, Yamamoto K, et le (2009). Sesquiterpene lactone parthenolide ameliorates bladder inflammation
DOI:http://dx.doi.org/10.7314/APJCP.2015.16.18.8119

Anti-tumor and Chemoprotective Effects of B.tomentosa

and bladder over-activity in cyclophosphamide-induced rat cystitis model by inhibiting NF- $x \mathrm{~B}$ phosphoryla-tion. $J$ Urol, 181, 2339-48.

Kolb J P. (2000). Mechanisms involved in the pro- and antiapoptotic role of NO in human leukemia. Leukemia, 14, 1685-94.

Lewis AM, Varghese S, Xu H, Alexander HR (2006). Interleukin-1 and cancer progression: the emerging role of interleukin-1 receptor antagonist as a novel therapeutic agent in cancer treatment. $J$ Transl Med, 4, 48.

Majumdar UK, Gupta M, Maiti S (1997). Antitumour activity of hygrophila spinosa on Ehrlich ascites carcinoma and sarcoma-180 induced mice. Ind J exp biol, 35, 473-7.

Malek TR (2003). The main function of IL-2 is to promote the development of T regulatory cells. J Leukoc Bio, 74, 961-5.

Mannangatti V, Ayyasamy B, Rangasamy M, Natesan S (2010). Antioxidant potential of ethanolic extract of Bauhinia tomentosa (Linn) flower. Res J Pharma BioChem Sci, 1, 143-7.

Manusama ER, Stavast J, Durante NM, Marquet RL, Eggermont AM (1996). Isolated limb perfusion with TNF alpha and melphalan in a rat osteosarcoma model: a new anti-tumour approach. Eur J Surg Oncol, 22, 152-7.

Moron MS, Depierre JW, Mannervik B (1979). Levels of glutathione, glutathione reductase and glutathione-Stransferase activities in rat lung and liver. Biochim Biophys Acta, 582, 67-78.

Murata M, Suzuki T, Midorikawa K (2004). Oxidative DNA damage by a hydroperoxide derivative of cyclophosphamide. Free Radic Biol Med, 37, 793-802.

Natesan S, Badami S, Dongre SH, Godavarthi A (2007). Antitumor activity and antioxidant status of the methanol extract of Careya arborea bark against Dalton's lymphoma ascites-induced ascitic and solid tumor in mice.J Pharmacol Sci. 103, 12-23.

Newman DJ, Cragg GM (2012). Natural products as sources of new drugs over the 30 years from 1981 to 2010. J Nat Prod, 75, 311-35.

Ouyang GF, Saio M, Suwa T, et al (2006). Interleukin-2 augmented activation of tumor associated macrophage plays the main role in MHC class I in vivo induction in tumor cells that are MHC negative in vitro. Int J Oncol, 28, 1201-8.

Preethi KC, Siveen KS, Kuttan R, Kuttan G (2010). Inhibition of metastasis of B16F-10 melanoma cells in C57BL/6 mice by an extract of Calendula officinalis L flowers. Asian Pac J Cancer Prev, 11, 1773-9.

Rajkapoor B, Jayakar B, Murugesh N, Sakthisekaran D (2006). Chemoprevention and cytotoxic effect of Bauhinia variegata against $\mathrm{N}$-nitrosodiethylamine induced liver tumors and human cancer cell lines. J Ethnopharmacol, 104, 407-9.

Rates SMK (2001). Plants as source of drugs. Toxicon. 39, 603-13.

Richard JS, Annet H, David KS, Jacquetine MM, Larry, DW (1997). Interleukin-6 structure-function relationship. Prot sci, 6, 929-55.

Ruttimann J (2007). Macrophages and nitric oxide: A deadly combination. J Exp Med, 204, 3057.

Sakthivel KM, Guruvayoorappan C (2012). Biophytum sensitivum: Ancient medicine, modern targets. J Adv Pharm Technol Res, 3, 83-91.

Sakthivel KM, Kannan N, Angeline A, et al (2012). Anticancer activity of acacia nilotica (1.) wild. ex. delile subsp. indica against dalton's ascitic lymphoma induced solid and ascitic tumor Model. Asian Pac J Cancer Prev, 13, 3989-95.

Sakthivel KM, Guruvayoorappan C (2013). Acacia ferruginea inhibits tumor progression by regulating inflammatory mediators TNF $\alpha$, iNOS, COX-2, IL-1 $\beta$, IL-6, IFN $\gamma$, IL-2, 
GM-CSF, and pro-angiogenic growth factor VEGF. Asian Pac J Cancer Prev, 6, 3909-19.

Siest G, Courtay C, Oster T, et al (1992). Gammaglutamyltransferase: nucleotide sequence of the human pancreatic cDNA. Evidence for a ubiquitous gammaglutamyltransferase polypeptide in human tissue. Biochem Pharmacol, 43, 2527-33.

Slingluff CL, Gina R, Petroni GV, et al (2003). Clinical and immunologic results of a randomized phase II trial of vaccination using four melanoma peptides either administered in granulocyte-macrophage colony-stimulating factor in adjuvant or pulsed on dendritic cells. J Clin Oncol, 21, 4016-26.

Small E J, Sacks N, Nemunaitis J, et al (2007). Granulocyte macrophage colony-stimulating factor-secreting allogeneic cellular immuno-therapy for hormone-refractory prostate cancer. Clin Cancer Res, 13, 3883-91.

Soiffer R, Hodi FS, Haluska F, et al (1998). Vaccination with irradiated autologous melanoma cells engineered to secrete human granulocyte-macrophage colony-stimulating factor generates potent antitumor immunity in patients with metastatic melanoma. Proc Natl Acad Sci, 95, 13141-46.

Strasak AM, Rapp K, Brant LJ, et al (2008). The vorarlberg health monitoring and promotion program study group: association of $\gamma$-glutamyl-transferase and risk of cancer incidence in men: a prospective study. Cancer Res, $\mathbf{6 8}$, 3970-7.

Tenhagen TL, Van der Veen AH, Nooijen PT, et al (2000). Low-dose TNF- $\alpha$ augments anti-tumor activity of stealth liposomal doxorubicin (DOXIL) in soft tissue sarcomabearing rats. Int J Cancer, 87, 829-37.

Trachootham D, Alexandre J, Huang P (2009). Targeting cancer cells by ROS-mediated mechanisms: A radical therapeutic approach? Nat Rev Drug Discov, 8, 579-91.

Verheul HM, Pinedo HM (2000). The role of vascular endothelial growth factor (VEGF) in tumor angiogenesis and early clinical development of VEGF-receptor kinase inhibitors. Clin Breast Cancer, 1, 80-4.

Zarei S, Schwenter F, Luy P, et al (2009). Role of GM-CSF signaling in cell-based tumor immunization. Blood, 25, 6658-68. 